\title{
Palgrave Dictionary of Emerging Markets and Transition Economics: Insights from Archival Research
}

\section{Jens Hölscher and Horst Tomann, eds.}

Basingstoke: Palgrave Macmillan UK, 2016, pp. XX + 589

ISBN 978-1-137-37137-9

doi:10.15179/ces.18.1.5

At the beginning of 2016, Palgrave Macmillan published the Palgrave Dictionary of Emerging Markets and Transition Economies: Insights from Archival Research, continuing its attractive book series entitled "Studies in Economic Transition". The book is edited by two renowned authors - Jens Hölscher, professor at Bournemouth University (also co-editor of the mentioned book series) and Horst Tomann, professor emeritus from the Free University Berlin. This lengthy book of 590 pages is organized in five basic parts dealing with monetary issues, institution building, policies, growth and development, and finally general wellbeing within the economies in question. Further, each part of the dictionary consists of a number of chapters, creating altogether 28 relatively independent but also interconnected papers written by a respectable group of 36 authors. This type of book "architecture" tracks the editors' idea to go after an already approved model given in The New Palgrave Dictionary of Economics, with its encyclopaediabased approach,but with articles that in addition to defining certain issues, also provide a deeper insight in the evolution of the phenomena explored, including the results achieved or just dilemmas raised within the corresponding debates 
over time. It should be also mentioned that the editors wanted to structure the book by tracking the sequencing that in their view characterizes the entire process of transition and market emergence. For that reason, in the forefront they put monetary issues, as the crucial point for initial stabilization of the economies in question, and continue with the founding of new market economy institutions and policies to shed light on the development results and actual well-being effects on a broader scale. In this review, I shall stick to the same sequencing in order to present some basic ideas and principal contents of the related articles.

Central bank independence (CBI), currency reform (CR), and financial sector restructuring (FSR) are highlighted in the first part of the book as being the crucial elements of monetary stabilization and external monetary cooperation in emerging market economies. Thus, the first chapter is devoted to analyzing the importance of CBI. Despite an undoubtedly accepted and promoted argument for a high independence level of the central bank in a transition economy, the analysis conducted by the authors (J. Bogoev and G. Petreski) brings about major findings that show how the association between $\mathrm{CBI}$ and inflation becomes significant only after a threshold level of overall liberalization of the economy. This implication may suggest that CBI might have been an ingredient in the overall transformation process but not a sufficient tool for lowering inflation, at least in the initial period of transition.

The issue of CR has been analyzed as a process that is typically connected with the redenomination of the existing currency in a transition country or its replacement by a new currency. The author of the chapter (K. Staehr) underlines that details of the implementation of a CR, and in particular of the accompanying policy measures, are of crucial importance for a successful CR completion. Namely, CR may be seen as a useful step in obtaining or retaining macroeconomic stability, but the outcome of this reform rests on the acceptance and credibility of the new currency. In fact, analyses show that the results of the initial CR and stabilization programs in transition countries were rather mixed while most of the countries experienced very large price jumps after the liberalization of prices 
and commerce. Later developments showed the undoubted importance of policy measures that should surround an implemented CR.

The third chapter (by A. Mullineux) reviews FSR, putting the focus on enterprise financing. The first step is establishing a commercial banking system (the first moves toward this goal the author finds in the Chinese experience in the 1980s, ignoring for some reason a much older Yugoslav experience). However, for a true success, privatization of both state-owned banks and state-owned enterprises was required, together with the resolution of inherited bad debts. A corporate governance system for banks, including regulatory and supervisory mechanisms, had to be put in place to underpin financial stability and introduce an efficient allocation of capital, particularly among small- and medium-sized enterprises (SME) and households. The next step should be taken towards capital developing, bond and equity markets, and encouraging financial innovation whilst guarding against financial instability, rent seeking and fraud. The chapter identifies policies that can be used to promote beneficial financial sector developments (e.g., development banks for large projects, together with cutting budget deficits and inflation) although sometimes the reader could have doubts about some of the proposed measures (when too much hope is put in financing small businesses, seen as "an engine of future development" in transition countries).

The choice of the exchange rate regime (ERR) is the next topic discussed in the dictionary. The author of the chapter (K. Staehr) insists that the ERR comprises the exchange rate arrangement and a number of complementary policies, including possible capital controls and monetary policy, and for that reason the right choice must consider many factors. Various advantages as well as possible weak points of the particular ERR are discussed within the chapter. The choice should take into account the preferences of the policy-makers, the prevalence and propagation of shocks, and the structure and functioning of the economy, but also factors such as the credibility and capacity of the authorities. It is important to emphasize, however, that neither the allocation nor the stabilization gains are guaranteed in practice. The author strongly supports the position of Calvo and Mishkin ("The Mirage of Exchange Rate Regimes for Emerging Market 
Countries") who see the ERR as only one policy choice and other choices —including reforms of institutions, markets, and government—are likely to play a larger role for long-term growth and welfare in most economies.

In the chapter on monetary stabilization (MS), monetary policy strategies are examined for transition economies in post-socialist Europe and Asia (author Z . Polanski). Starting from the definition of MS, the analysis covers the role of money under socialism and continues with MS programs from the early period of transition onwards. Particular attention is devoted to the main problems related to monetary strategy implementation during transition. The chapter ends with a short discussion of current challenges revealed after the crisis, where the crucial issue becomes development of macroprudential instruments which should supplement monetary policy for dealing with imbalances in financial and real estate markets. Finally, a brief survey of current monetary policy regimes in transition economies is offered.

Regional monetary cooperation among developing, transitional, and emerging economies is the main topic of the closing chapter (B. Fritz and L. Mühlich) of part one in the dictionary. Although not so frequently present among transition economies (apart from some initiatives within the Commonwealth of Independent States and to a certain extent some targeting of the euro zone), the chapter gives an interesting analysis of the possible effects when monetary cooperation is established. The authors compare the first ideas presented in various variants of optimal currency area theory and some later considerations finding that even small initiatives may contribute to mitigating the effects of exogenous shocks within the region. In addition, the analyzed forms of regional monetary cooperation that may or may not develop into a full monetary integration provide possibilities to contain uncontrolled devaluations and thus increase regional coordination of macroeconomic policies. This is particularly valid for exchange rate coordination that seems to be the key in achieving stabilization gains, but at the same time it requires the highest level of monetary policy cooperation between the member countries. 
The second part of the book examines the difficulties of institution building during transition. The analysis commences with an inspiring paper (M. Myant) on the diversity of capitalism that could be implemented in transition economies. The chapter starts with the reasons for an incorporation of institutions into interpretations of transition by the late 1990s that made a shift from the previously dominant view that had reduced progress towards a market economy to liberalization and private ownership. This happened because performance and behavior of transition economies through the 1990s showed that formal liberalization, deregulation, and privatization had very diverse consequences. Going further from this point, the analysis of institutional change leads the reader through some disputable fields like Polanyi's study of capitalist development that can provide a basis for explaining the evolution of at least some of the different kinds of post-socialist capitalism. Then the varieties-of-capitalism approach in its best known form (liberal vs. coordinated market economy) is discussed and followed by considerations on how the latter framework can be adapted and applied for Central and Eastern Europe and what the differences are between these countries and those that emerged out of the break-up of the Soviet Union. Although the author correctly states in the conclusion that an institutionalist approach is at the least an important counterweight to more traditional and orthodox neoclassical views, it remains open what real institutional arrangement could be achieved under the very specific circumstances in various countries and hybrid systems that are emerging along transition processes.

The next chapter (by C. Hartwell) examines institutional reform in Central and Eastern Europe and the former Soviet Union, with a focus on the various policies enacted as well as the timing and sequencing of institutional reforms. Basically, the author argues that there is a firm interaction between policies and institutional reforms. However, despite some obvious connection of this type, giving primacy to policies as suggested could bring us to a quite extreme position that finds institutions to be always managed, shaped and/or governed by policies. It seems that such a position very much influences the author of this chapter predicting in a way his conclusion that countries that were faster in policy change were also 
more successful in institution building both in the shorter and in the longer run, which is a doubtful analytical outcome in regard to the presented arguments but also a conclusion that could not be easily confirmed by other analysts.

The third chapter on institution building analyzes property rights. The author (C. Hartwell) considers the development of property rights as the most important institutional reform during transition that has been comparatively neglected in some countries in favor of other institutions. The chapter looks at the theoretical basis behind the determination of property rights and how various theories apply (or do not apply) in a transition context. Further on, the experience of various transition countries was examined and how and why property rights protection diverged across economies. The key result of this examination is that property rights illustrate the "indivisibility of reforms" in transition, but that there must be a concerted effort to continually protect these rights as other, mainly political, institutions grow around them. The author again presents an original though insufficiently proved conclusion that the development of property rights in transition appeared to be determined by both economic and political factors, with economic factors predominating in the early years and political factors taking over as the transformational recession and period of extraordinary politics passed.

The issue of corporate governance under transition occupies the next chapter. The author (S. Letza) looks at the current debate on corporate governance as being somewhat "polarized" between, on the one hand, the shareholding paradigm and, on the other hand, the stakeholding paradigm. Both camps of the debate rely on a homeostatic and entitative conception of the corporation and its governance structures. Consequently, they suffer from inadequate attention to the underlying philosophical presuppositions in which the static approach is rooted. To avoid the traditional trap in theorizing, an alternative approach, referred to as the processual approach, is proposed. The author states that a processual perspective steps out of the trap of, and goes beyond, an "eitheror" way of thinking and theorizing since it regards corporate governance as 
an emergent pattern of dynamic governing processes, actions, and activities in specific social and historical contexts.

The institution building section ends with a chapter on specific business constraints in low-income transition economies of Central Asia, such as the Kyrgyz Republic and Tajikistan. The author (K. Djalilov) explores enterprise surveys conducted by the World Bank and the EBRD that found major business barriers in these countries to be: political instability, practices of the informal sector, tax rates, and corruption. The chapter provides suggestions for future possible developments in overcoming these business barriers.

The third part of the dictionary analyzes issues related to economic policy. The first discussed issue concerns economic growth and human development. Although human development and economic growth are two different paradigms that imply different objectives, measurement techniques and policies, they are interconnected and mutually reinforce each other. The authors of this chapter (E. Chiappero-Martinetti, N. von Jacobi and M. Signorelli) focus on these two different paradigms of socio-economic progress: while both paradigms have evolved in different periods, emerging from rather different schools of thought, they both address the open question of how societies can improve their quality of living. Since inequality, both monetary and non-monetary, and contextual features, such as local economic structure or institutions, further seem to play a crucial role in linking the outcomes of economic growth to the outcomes of human development, focus is placed on the specific problems of transition countries that used to be characterized by "full employment" and comparatively high levels of human capital, but also by low productivity and underemployment.

An interesting contribution can be found in the next chapter, dealing with competition policy (J. Hölscher). For transition economies that become new member states of the EU, state aid is a sensitive issue, in particular for politicians, but also for society at large. Large employers, for which the state was previously responsible, carry the heaviest burden in the process of industrial restructuring during transition. Still, once having entered the EU as full members, the new 
members from the East appear to have been converging into rather stringent competition cultures: comparative analysis suggests that enforcement has gradually become as effective and strict in the East as is the case in the West. We may conclude that state aid in the new member countries of the EU today is not granted more generously than amongst the old members. It also appears not to be more targeted at individual firms or industries. On the other hand, the author leaves the readers with a dilemma - whether such an outcome could be cheered as an entirely correct and advantageous one.

The next chapter deals with the process which brought about ten countries of Central and Eastern Europe (CEEC) to join the EU between 2004 and 2007. Topics such as recent EU enlargement, the adhesion of Croatia in 2013, the future perspective of enlargement opened by the East partnership, and the situation of the current candidates to the EU are also considered. The author (P. Tridico) analyzes the economic growth of those countries as well as institutional development and development of other reforms, finding that in the case of CEEC, the EU accession — both as an expected event and as a mere act of accession - had a positive role regarding economic growth, reforms and convergence which could explain the much slower and modest advancement in former Soviet republics. At the same time, the old EU member states (EU-15) benefited greatly from trade with CEEC and foreign direct investments directed to CEEC.

The following chapter examines the issue of sustainability of public budgets, with special reference to emerging markets and transition economies. According to the authors (C. Hartwell and M. Signorelli), no matter which conception is settled upon, sustainability is dependent upon development of the necessary institutions for fiscal policy-making. Moreover, they state that it is impossible to divorce fiscal policy-making from the political institutions that comprise a government, the interests that can pressure the expenditure process, and the general cultural consensus on the proper role of government. Consequently, they put forward a pretty unusual argument finding that a lesson learned from transition economies is that sustainability is almost always a question of expenditure rather than revenue because expenditure decisions are almost always entirely concentrated 
in a government. Hence, sustainable expenditures can be implemented even if there is political opposition, while revenue generation, having adverse effects on the real economy, is to some extent out of the government hands.

The final chapter on policy issues examines the bad-asset problem and demonstrates that it is not a mere consequence of inefficiency and mismanagement, but has its origin in the system change. The author (H. Tomann) identifies these systemic reasons as a specific stock-flow problem in transition economies. In a Keynesian perspective, the conclusion is clearly to release old debts and clear the balance sheets. The chapter reviews different strategies of how to distribute the burden and their impact on investment activity and growth, price stability, the future tax burden, and social security, respectively. It briefly describes how the bad-asset problem has been tackled, particularly focusing on a case study of East Germany. Finally, an outlook is given on the recent financial crisis which calls for shared responsibility in fiscal policy.

The fourth part of the dictionary is dedicated to growth and development, discussing issues like entrepreneurship, innovation, foreign direct investments (FDI), but also migration, trade liberalization etc. In the opening chapter, the author (S. Ayatakshi) explores the issue of entrepreneurship in a broader context, connecting it finally with transition economies and the growing number of private firms through privatization but also of those established de novo, frequently less present in analytical papers. Special attention is given to SMEs, social entrepreneurship and women in entrepreneurship in transition.

The chapter on innovation refers particularly to new products and production processes as the most important types of innovation and primarily to the role of innovation and technology in economic development in emerging and transition economies. The theoretical concept of national innovation systems defined by the author (J. Gunther) offers the framework for discussing the role of heterogeneous actors, their cooperation, and institutions in innovation processes. It is important to point out that the author is among the few authors presented in the book who draw attention to the recent debate on the lack of economic and 
particularly industrial policy as a means that could shift transition and emerging economies from technological imitation to original innovation, which requires not only economic but also societal endeavors.

Migration is the theme of the next chapter. The authors (M. Chowdhury and $\mathrm{H}$. Telli) aim to provide an overview of the economics of migration starting with an exposition on the nature and the facts of contemporary world-wide migration. This is followed by sections covering determinants of migration; migration and development; migration and innovation; and migration, trade and foreign direct investment. The chapter addresses both theoretical and empirical literature on migration and discusses the past and present issues of the economic migration literature and how the literature may evolve in the future, making it a good basis for academics and/or practitioners and policy-makers when faced with different issues of economic migration.

In the fourth chapter of part four, the reader can find a comprehensive and very well founded article on trade liberalization (TL). The author (S. Acharya) presents a survey of theoretical and empirical results regarding the impact of TL on production and growth but also on distribution and poverty. Although most of the studies find that trade reform is accompanied by productivity growth, technology advancement, falling mark-ups, and a reshuffling of resources toward more efficient firms, in some cases the evidence fails to confirm these results when less developed countries are concerned. Studies that analyze distributional impacts of trade openness and are usually based on cross-country comparisons, country-specific partial analysis, and general equilibrium analysis, which do not offer any robust conclusion. However, general system approach is more comprehensive and more recent studies reveal that TL of the developing world is growth-enhancing; however, economic restructuring is deemed essential in making the impacts pro-poor.

The concluding chapter of this part of the book looks at key issues concerning inward foreign direct investment (FDI) in transitional countries from Europe and Central Asia. The authors (G. Okafor and A. Webster) consider the 
important determinants for inward FDI in these economies such as market size, natural resource endowments and institutional quality. They also examine the contribution of inward FDI to the process of economic transition and to economic growth. Although the connection between economic growth and inward FDI is more complex than might be expected, evidence does indeed suggest a strong association between the two in transitional countries, but the causality (i.e., who comes first) is pretty blurred. Finally, structural change is an important part of the process of economic transition, in which inward FDI has at least a significant potential to add a certain contribution.

The final, fifth part of the dictionary could raise additional interest since it deals with the issues of general well-being that are rarely present in transition analyses, particularly regarding specific aspects such as social responsibility, trust, happiness etc. The first chapter examines the various kinds of convergence and divergence and how their existence has influenced policy choices, particularly the European Currency Union. Instead of offering a definite conclusion, the authors (G. Nell and M. Signorelli) examine the challenges that transition economies could face, especially those posed by reforms undertaken for the purpose of meeting with European Currency Union guidelines and laws, and the specific issues for least developed economies. Finally, the authors point out that theoretical and empirical investigations on complex convergence/divergence phenomena are useful for designing better economic and institutional policies.

One of the most visible and sensitive outcomes of the reforms associated with transition from planned to market economies is the rise in income inequality. This important and recently much-discussed topic is covered in the second chapter of part five. The authors (C. Perugini and F. Pompei) find that in the early stages of transition, the approach to reforms and the macroeconomic conditions determined the pattern of income inequality, and in later stages the drivers of wage and income disparities typical of modern market economies became dominant (technological change, labor market institutional settings, the position of each economy in the international division of labor, welfare models). The authors provide a very convincing empirical and a conceptual overview of 
income inequality during and after transition in Central and Eastern European, Western Balkan, and former Soviet Union countries, discussing the complex interplay of the many relevant forces.

The next chapter examines whether the changing paradigm of business philosophy during transition may encourage some rethinking of the business activity of enterprises and expand their responsibility limits. The authors ( $S$. Lyeonov, T. Vasylyeva and A. Lasukova) examine some key prerequisites for the formation of the corporate social responsibility concept. They define the essence of the concept and its multidimensional level and examine the differentiation between corporate social responsibility and corporate social sustainability. The characteristics of the main indices and standards which are used in the practice of socially responsible business are mentioned together with the necessity of the creation and publication of non-financial reports.

Probably the most critical contribution within the whole book is the one devoted to mass privatization programs. The authors (D. Irdam, G. Scheiring and L. King) find that the challenges of transition were mistakenly perceived by radical reformers as a simple task of freeing market forces and privatizing enterprises. Though it quickly turned out that initial conditions and path dependence matter much more than expected by neoclassical economic recipes, the idea of a quick-designer capitalism dominated during the early years of transition. The collapse of the state contributed to the emergence of a patrimonial capitalism widely differing from the type of capitalism envisioned by the designers of shock therapy. Moreover, the failure of the state and the collapse of the economic system both, in turn, led to a demographic catastrophe. Thus, in short, mass privatization programs according to the authors of this chapter were quite possibly the worst available type of privatization and with destructive consequences.

The dictionary continues with another interesting chapter devoted to the issue of employee financial participation (EFP). The author (D. McCarthy) finds that the primary rationale for EFP is to improve firm performance through the aligning of employee objectives with those of the firm. However, he also finds that there 
is even more evidence of a relationship with softer outcomes associated with employee attitudes and behavior. Therefore, it is not surprising that research findings highlight the importance of not viewing EFP in isolation and point to the role of scale of returns, involvement in decision-making and corporate culture in influencing outcomes. This chapter also discusses the development of EFP in the European context, with particular focus on its development in the transition economies of Central and Eastern Europe.

The next chapter examines the role (and the scope) of trust in transition economies. It is known that trust can reduce transaction costs. In particular, extended trust plays a crucial role in economic development: higher levels of generalized trust at the country-level lead to higher growth rates. However, the author of the chapter (A. Rebmann) warns readers that transition countries are lacking in extended trust. The low levels of extended trust can be ascribed to a legacy from the communist period where "states set out to destroy old social bonds in order to assert their authority". This could be a somewhat disputable argument, but the low level of trust was deepened by obvious instability and weakness of institutions at the beginning of transition, which made the creation of generalized or institutional trust difficult. The article also covers the major debates, such as whether institutional trust in transition engenders generalized trust or vice-versa, whether particular trust undermines extended trust, and whether regulations act as generalized trust substitutes.

Based on economic and sociological research, the author of the last chapter (E. Selezneva) examines the stability and/or instability of behavioral patterns across developed countries and countries in transition. At first the chapter introduces the notion of subjective well-being (SWB) and its components and then it studies the existing SWB gap between developed countries and countries in transition and defines the socio-demographic characteristics of the winners of transition. Further on, the focus moves to socio-economic determinants of well-being in transition, highlighting the role of income, absolute and relative, labor market participation, and employment status. Finally, the author investigates the role of 
societal and institutional characteristics, which are increasingly recognized as being more important than the economic ones.

As can be seen from the brief survey of the main dictionary contents presented above, the book is an interesting and instructive volume that could attract the attention of all those who want to study, learn, teach and/or systematize basic facts about the recent transformation of state-controlled economies into a market model. The dictionary covers 28 essential issues truly relevant for any analysis of transition, explaining their meaning, role and impact. It is particularly valuable that the discussed issues are seen from a perspective of their development and evolution either in academic disputes and understanding or in applied transformation schemes and policies recommended. This is in particular visible in the chapters on macroeconomic stabilization where special concern is given to the post-2007 crisis events and changes in paradigms that followed. However, this kind of approach cannot be found with all the authors and is primarily lacking or insufficient in some chapters on institutional building and on economic policies and growth. In consequence, the reader is sometimes deprived of early but important milestones elaborating criticism and even scepticism regarding some recommended concepts, and of the new findings that decisively advocate new growth models for transition economies.Despite this fact and a sometimes uneven critical approach by different authors, the book and the editors still deserve a huge credit and gratefulness for a stimulative undertaking and the result they bring about.

\section{Božidar Cerović}

Faculty of Economics, University of Belgrade, Serbia 